\title{
Genetic Polymorphisms Associated to Folate Transport as Predictors of Increased Risk for Acute Lymphoblastic Leukemia in Mexican Children
}

\section{OPEN ACCESS}

Edited by:

José A. G. Agúndez,

University of Extremadura, Spain

Reviewed by:

Vita Dolzan

University of Ljubljana, Slovenia

Juergen Reichardt,

Yachaytech University, Ecuador

*Correspondence:

Ismael Lares-Asseff

ismaelares@yahoo.com

Luis A. Quiñones

lquinone@med.uchile.cl

Specialty section

This article was submitted to

Pharmacogenetics and

Pharmacogenomics,

a section of the journal

Frontiers in Pharmacology

Received: 13 May 2016

Accepted: 21 July 2016

Published: 05 August 2016

Citation:

Zaruma-Torres F, Lares-Asseff I,

Lima A, Reyes-Espinoza A, Loera-Castañeda V, Sosa-Macías M,

Galaviz-Hernández C,

Arias-Peláez MC, Reyes-López MA

and Quiñones LA (2016) Genetic

Polymorphisms Associated to Folate

Transport as Predictors of Increased

Risk for Acute Lymphoblastic

Leukemia in Mexican Children.

Front. Pharmacol. 7:238

doi: 10.3389/fphar.2016.00238

\begin{abstract}
Fausto Zaruma-Torres ${ }^{1,2}$, Ismael Lares-Asseff ${ }^{1 *}$, Aurea Lima ${ }^{3}$, Aarón Reyes-Espinoza ${ }^{4}$, Verónica Loera-Castañeda ${ }^{1}$, Martha Sosa-Macías ${ }^{1}$, Carlos Galaviz-Hernández ${ }^{1}$, María C. Arias-Peláez ${ }^{5}$, Miguel A. Reyes-López ${ }^{6}$ and Luis A. Quiñones ${ }^{7 *}$

${ }^{1}$ Pharmacogenomics Academia, National Polytechnic Institute-CIIDIR, Durango, Mexico, ${ }^{2}$ School of Biochemistry and Pharmacy, University of Cuenca, Cuenca, Ecuador, ${ }^{3} \mathrm{CESPU}$, Instituto de Investigação e Formação Avançada em Ciências e Tecnologias da Saúde, Gandra, Portugal, ${ }^{4}$ State Center of Cancerology of SSA, Durango, Mexico, ${ }^{5}$ Institute of Scientific Research of the University Juarez of State of Durango, Durango, Mexico, ${ }^{6}$ Center of Biotechnology Genomics, National Polytechnic Institute, Reynosa, Mexico, ${ }^{7}$ Pharmacological and Molecular Program, Laboratory of Chemical Carcinogenesis and Pharmacogenetics (CQF), Faculty of Medicine, ICBM, University of Chile, Santiago, Chile
\end{abstract}

Acute lymphoblastic leukemia (ALL) is a frequent neoplasia occurring in children. The most commonly used drug for the treatment of ALL is methotrexate (MTX), an anti-folate agent. Previous studies suggest that folate transporters play a role in ALL prognosis and that genetic polymorphism of genes encoding folate transporters may increase the risk of ALL. Therefore, the main goal of this study was to determine the associations among six genetic polymorphisms in four genes related with the folate transporter pathway to determine a relationship with the occurrence of ALL in Mexican children. A case-control study was performed in $73 \mathrm{ALL}$ children and 133 healthy children from Northern and Northwestern Mexico. COL18A1 (rs2274808), SLC19A1 (rs2838956), ABCB1 (rs1045642 and rs1128503), and ABCC5 (rs9838667 and rs3792585). Polymorphisms were assayed through $\mathrm{QPCR}$. Our results showed an increased ALL risk in children carrying CT genotype $(\mathrm{OR}=2.55, \mathrm{Cl} 95 \% 1.11-5.83, p=0.0001)$ and $\Pi$ genotype (OR = 21.05, Cl 95\% 5.62-78.87, $p<0.0001)$ of COL18A1 rs2274808; in SLC19A1 rs2838956 AG carriers (OR = 44.69, Cl 95\% 10.42-191.63, $p=0.0001)$; in $A B C B 1$ rs1045642 $\Pi$ carriers $(\mathrm{OR}=13.76, \mathrm{Cl} 95 \% 5.94-31.88, p=0.0001)$; in ABCC5 rs9838667 AC carriers (OR $=2.61$, Cl 95\% 1.05-6.48, $\mathrm{p}<0.05$ ); and in ABCC5 rs3792585 CC carriers (OR = 9.99, Cl 95\% 3.19-31.28, $p=0.004)$. Moreover, several combinations of genetic polymorphisms were found to be significantly associated with a risk for ALL. Finally, two combinations of ABCC5 polymorphisms resulted in protection from this neoplasia. In conclusion, certain genetic polymorphisms related to the folate transport pathway, particularly COL18A1 rs2274808, SLC19A1 rs2838956, $A B C B 1$ rs1045642, and ABCC5 rs3792585, were associated with an increased risk for ALL in Mexican children.

Keywords: acute lymphoblastic leukemia, folate transporters, genetic polymorphisms, methotrexate, molecular epidemiology 


\section{INTRODUCTION}

Acute lymphoblastic leukemia (ALL) is a malignant cancer disorder with an etiology not yet completely understood (Zeller et al., 2005). Its prevalence of $\sim 34$ to 35:100,000 in the Mexican pediatric population, accounting for $80-85 \%$ of all childhood leukemia found in northwestern Mexico (Rodríguez et al., 2010). Many factors, such as, physical, chemical, and genetic causes, are associated with ALL susceptibility in pediatric patients (Skibola et al., 1999).

The choice of chemotherapy treatment for ALL is based on the St. Jude Total XV protocol with antifolate drugs, as methotrexate (MTX; Pui et al., 2009, 2010). Three cellular mechanisms for folate transport have been identified: folate receptors (FR), reduced folate carrier (RFC), and the newly described proton-coupled folate transporter (PCFT). RFC 1 (reduced folate carrier 1), a $57-65 \mathrm{kDa}$ integral transmembrane and energy-dependent protein, also called SLC19A1, member of the SLC19 family of solute carriers belonging to the ABC (ATPbinding cassette transporter family; Takatori et al., 2006) is the primarily way for folate or antifolate drugs transport (Sirotnak and Tolner, 1999; Ganapathy et al., 2004).

RFC1 is encoded by RFC1 (SLC19A1) gene located at chromosome 21 (locus 21q22.2-q22.3; Moscow et al., 1997; Jansen and Pieters, 1998). Moscow et al. demonstrated that RFC1 is over-expressed in cancer cell lines, mainly in breast cancer and leukemia. This over-expression produces an increased in vitro cytotoxicity due to contact with MTX, which may explain the affinity of these receptors to the anti-folates (Moscow et al., 1997). RFC1 transport function is enhanced by another protein, Collagen alpha-1 (XVIII) chain, encoded by COL18A1 (locus 21q22.3), and has been described as crucial for malignant processes due to endostatin production (Digtyar et al., 2007), which is a powerful angiogenesis and tumor growth inhibitor (Sertie et al., 2000).

Conversely, MDR1 and MRP5, belonging to an important efflux transporter protein family of drugs and their metabolites called multidrug resistance proteins (MDR and/or MRP), have been shown to be important in the treatment of cancer cells (Higgins, 2001; Holland and Holland, 2005). These proteins are encoded by highly polymorphic genes $(A B C B 1$ and $A B C C 5)$ that have been associated with increased ALL risk and have also been implicated in oncologic treatment interpatient variability (Gottesman et al., 2002; Brisson et al., 2015), specifically against anti-folate drugs (Wielinga et al., 2005), leading to an increased risk of relapse (Choi, 2005). There is evidence that MRP5 transporter is overexpressed in the biological barriers of the brain, which could support the idea that ALL patients frequently relapse in the central nervous system (Warren et al., 2009); therefore, some genotypic modifications in the gene $A B C C 5$ would enhance the severity of ALL. Disruptions of the homeostasis of the one-carbon metabolism are attributed to folate deficiencies, leading to DNA damage. Therefore, genetic defects and polymorphisms in these pathways may have influence in cancer susceptibility and therapeutic response (Homberger et al., 2000).
Therefore, in this research we aimed to evaluate the influence of six genetic polymorphisms in these membrane folate transport associated-proteins on the ALL susceptibility development, to expand the understanding of these variants as potential genetic risk factors for ALL pathogenesis.

\section{MATERIALS AND METHODS General Study Design}

This research was performed as an observational prospective, case-control, association study. This study was approved on April 17th, 2013 by the CECAN Ethics and Research Committee, Durango, Mexico, in accordance with the Helsinki Declaration, Good Clinical Practices (CGP), and Mexican General Health Law. Signed informed assent and consent were obtained from all children, and patients and controls were tutored before participation in the study.

Seventy-three pediatric ALL patients were admitted between May 2013 and December 2014 to the Hematology-Oncology Unit, Durango State Cancer Center (Centro Estatal de Cancerología, CECAN), Durango, Mexico. The ALL diagnosis was based on the Franco-American British Association criteria (Lilleyman et al., 1986). One hundred and thirty-three children without ALL were used as the control group.

\section{Genotyping}

DNA extraction was performed using total blood samples obtained by venous punctures using a commercial kit (MachereyNagel ${ }^{\circledR}$, Düren, Germany). After extraction, DNA integrity and purity were evaluated by horizontal electrophoresis in a $1 \%$ agarose gel stained with ethidium bromide. The concentration and quality were analyzed in a NanoDrop $2000^{\circledR}$ (Thermo Scientific, Wilmington, DE, USA). Determination of single nucleotide polymorphisms (SNPs) was analyzed using real-time polymerase chain reaction (qPCR) by 48 -well plate StepOne ${ }^{\circledR}$ Real-Time PCR system (Applied Biosystems, Carlsbad, CA, USA) with TaqMan probes by Applied Biosystems StepOne ${ }^{\mathrm{TM}}$ (Foster City, CA, USA). The SNPs COL181 (rs2274808), SLC19A1 (rs2838956), ABCB1 (rs1045642, rs1128503), and ABCC5 (rs9838667, rs3792585) were determined by a typical reaction containing $5 \mathrm{ng} / \mu \mathrm{l}$ of DNA, $0.5 \mu \mathrm{L}$ of 20X TaqMan SNP genotyping assay and $5.0 \mu \mathrm{L}$ of $2 \mathrm{X}$ TaqMan Genotyping Master Mix (Foster City, CA, USA).

\section{Statistical Analyses}

Hardy-Weinberg equilibrium (HWE) and binding disequilibrium analyses were conducted using expected and observed genotypic and allelic frequencies in the study population. The SNPStats (2006, Catalan Institute of Oncology, Barcelona, Spain) software was used (Solé et al., 2006).

The relative risk associations of the COL18A1, ABCB1, and $A B C C 5$ genetic polymorphisms with ALL susceptibility were assessed and were expressed as an odds ratio (OR) or a $p<$ 0.05 with a 95\% confidence interval (CI 95\%). In addition, analyses of the associations between binary combinations of polymorphisms within the same locus and ALL were made to establish the relationship with the pathology. Finally, we 
developed an artificial neural network architecture of three layers. The first layer with covariates and factors, the second and hidden layer was from 60 to 2 neurons, and the third layer was the presence or absence of ALL (defined as the dependent variable). SAS v9.0 (USA, 2002) and Statistica v7 (USA, 2004) softwares were used. Fifty subjects were used for the training phase. The best model was obtained by comparison through the $2 \mathrm{log}$ Likelihood criteria and with the lower relative classification error.

\section{RESULTS}

Pediatric ALL patients and the controls showed a median age of 7.92 and 5.85 years, respectively. The anthropometric characteristics and biological parameters are presented in Table 1. As expected, a difference in the pathognomonic variables was observed between the groups.

Table 2 shows the allelic and genotypic frequencies for the study groups and HWE values for the control group. The results indicated five evaluated SNPs were in HWE, except $A B C B 1$ (rs1128503). In addition, we determined significant differences in allelic frequencies between SNPs.

To analyze the binary association responses, five inheritance models were estimated (codominant, dominant, over-dominant, recessive, and log-additive; Solé et al., 2006; Table 3). The best model estimation was determined as a function of lower values using the Akaike Information Criterion (AIC) and Bayesian Information Criterion (BIC) compared to a reference model (codominant: $X X$, wild type; $X Y$, heterozygous; $Y Y$, homozygous) Finally, the association with risk for ALL was estimated.

The associations among polymorphisms and ALL were determined by the OR test (CI 95\%, $p<0.05$ ). The results shown in Table 3 emphasize that the CT carriers for COL18A1 rs2274808 have a significant risk for ALL (OR = 2.55; CI95\%, 1.11-5.83). This result was also found in the dominant model CT-TT in relation to the wild type genotype. For SLC19A1 rs2838956, the best model was an over-dominant strategy where $A G$ subjects showed an atypical association with values of $\mathrm{OR}=$ 44.69.

Moreover, $A B C B 1$ rs1045642 increased the ALL risk for subjects carrying the $T T$ genotype in both the codominant and recessive models. The $A B C B 1$ rs1128503 did not result in a risk association to ALL.

The AC genotype for ABCC5 rs9838667 SNP was associated with ALL susceptibility (OR = 2.61, CI 95\% 1.05-6.48). However, the $A B C C 5$ rs3792585 SNP showed an increased risk for ALL in subjects carrying the CC genotype, which was the same result found in the recessive model.

Table 4 shows significant paired combinations for the closest SNPs in each gene and their association with ALL susceptibility. The results indicated that the COL18A1 (rs2274808)+SLC19A1 (rs2838956) combination, in relation to the wild type genotype $(C C+A A)$, had a significant association to ALL among the $C C+A G, C T+A G, T T+A G$, and $T T+G G$ combinations. The combination of ABCB1 SNPs (rs1045642+rs1128503), particularly the combinations of $T T+C T$ and $T T+T T$, presented a significant association to ALL. Finally, the total homozygote combination of $C C+C C$ showed an increased risk association with ALL (OR: 5.33, CI 95\% 2.59-1097). In contrast, the $A C+T T$ and $A C+T C$ combinations were shown to be protective against ALL.

The artificial neural network analysis determined that the best general model was that of one layer with 48 hidden

TABLE 1 | Anthropometric characteristics and biochemical parameters of subjects.

\begin{tabular}{|c|c|c|c|}
\hline Variable & Case $N=73$ (median, range) & Control $N=133$ (median, range) & $p$-value* \\
\hline Age(years) & $7.92(1.15-18.08)$ & $5.85(1.43-16.13)$ & 0.022 \\
\hline Gender (male/female) & $40(54.79) / 33(45.21)$ & $62(47 \%) / 71(53 \%)$ & 0.612 \\
\hline Body Weight (Kg) & $17.5(11.4-55.1)$ & $22.9(15.3-53.7)$ & 0.120 \\
\hline Height (m) & $1.07(0.65-1.71)$ & $1.22(0.67-1.63)$ & 0.216 \\
\hline Body surface $\left(\mathrm{m}^{2}\right)$ & $0.67(0.43-1.7)$ & $0.77(0.57-1.34)$ & 0.450 \\
\hline $\mathrm{BMI}\left(\mathrm{Kg} / \mathrm{m}^{2}\right)$ & $16.65(12.36-28.1)$ & $21(18.5-27.5)$ & 0.030 \\
\hline Time of treatment (weeks) & $76(25-289)$ & - & - \\
\hline Dose MTX (low-high) & $40.1 \mathrm{mg} / \mathrm{m}^{2}-5 \mathrm{~g} / \mathrm{m}^{2}$ & - & - \\
\hline Hemoglobin (g/dL) & $11.97(7.00-16.8)$ & 12.55 (11.06-14.3) & 0.876 \\
\hline Hematocrit (\%) & $35.45(27.2-47.0)$ & $36.6(34.6-45.1)$ & 0.667 \\
\hline Erythrocyte (cell/mm³) & $4.15(2.85-5.89) \times 10^{6}$ & $4.3(4.0-6.54) \times 10^{6}$ & 0.890 \\
\hline Leukocyte (cell/mm³) & $3.61(1.079-17.6) \times 10^{3}$ & $7.06(5.9-14.2) \times 10^{3}$ & 0.011 \\
\hline Platelet $\left(\right.$ cell $\left./ \mathrm{mm}^{3}\right)$ & $185.2(22.2-378) \times 10^{3}$ & $255(241-790) \times 10^{3}$ & 0.003 \\
\hline AST (UI/L) & $36.85(0.4-149)$ & $14.0(9.2-39.5)$ & 0.010 \\
\hline ALT (UI/L) & $46.6(2.3-210)$ & $19.4(1.9-69)$ & 0.006 \\
\hline Uric Acid (mg/dL) & $3.42(2.05-4.77)$ & $3.77(3.1-4.86)$ & 0.758 \\
\hline Urea(mg/dL) & 11.49 (8.89-61.75) & $34.2(10.7-63.2)$ & 0.035 \\
\hline Creatinine (mg/dL) & $0.70(0.24-1.54)$ & $0.8(0.42-1.32)$ & 0.870 \\
\hline Alkaline phosphatase (UI/L) & 257 (46-359) & $62(42-335)$ & 0.001 \\
\hline
\end{tabular}

${ }^{*} p<0.05$. 
TABLE 2 | Allele and genotype frequencies of COL18A1, SLC19A1, ABCB1, ABCC5 polymorphisms in subjects.

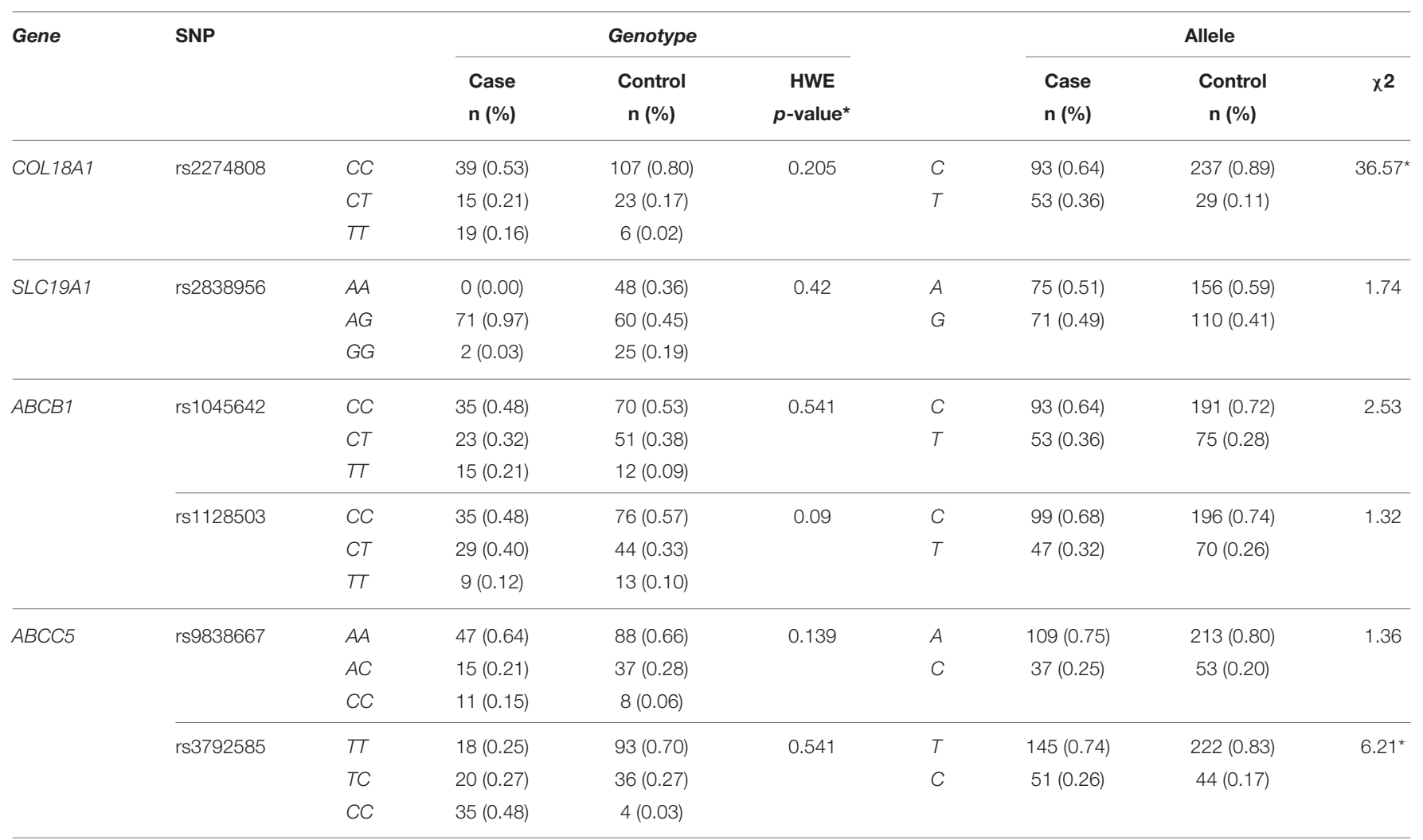

${ }^{*} p<0.05$.

neurons, an error-assay of $11.7 \%$ and an error-training of $14.8 \%$, respectively. The results indicated the most important normalized variables and pondered percentages for a response to ALL were $A B C B 1$ rs1045642 (72.8\%), COL18A1 rs2274808 (56.7\%), and ABCC5 rs3792585 (40.9\%), resulting in the following regression expression:

$$
\begin{aligned}
\text { ALL susceptibility }= & 4.201-0.921^{*} \text { rs } 2274808-1.647 \\
& * \operatorname{rs} 1045642-1.066{ }^{*} \text { ABCC5 rs3792585. }
\end{aligned}
$$

\section{DISCUSSION}

Pharmacokinetics, that is, absorption, distribution, metabolism, and excretion (ADME) describe the disposition of a xenobiotic within an organism. The four processes all influence the drug exposure to the tissues and hence, influences efficacy and safety of a compound/drug. In this sense, as in many other compounds, $\mathrm{ADME}$ process for folates requires membrane transporters (e.g., RFC1, ABC; Lage, 2008; Wolking et al., 2015). Due to its role on nucleotide metabolism and DNA synthesis, polymorphisms in genes associated to folate pathways may have influence in cancer susceptibility and chemotherapeutic response to methotrexate, an antifolate-antineoplastic drug (Ross and Doyle, 2004; Steinberg et al., 2007; Galbiatti et al., 2013). It has been shown that SNPs in folate-associated pathways give rise to different phenotypes with direct clinical implicances and/or pathological specific reactions (O'leary et al., 2006).

In order to evaluate this, in this study we analyzed six polymorphisms in genes RFC1 and ABC's and also COL18A1 (influencing the activity of these transporters), in relation to the risk of occurrence of ALL.

Our results suggest that COL18A1 rs2274808 could represent a risk factor for ALL. In addition, the dominant model, which groups these 2 subpopulations, suggests a similar behavior. The activity of COL18A1 rs2274808 was further validated by a study which determined that a defect in COL18A1 would change endostatin synthesis in a Salvadorian population (Mahajan et al., 2010), consequently leading to an antiangiogenic disorder, such as Knoblock syndrome and ALL; however, some authors have indicated that children with ALL have variable levels of endostatin (Dagdas et al., 2011), which makes it difficult to accurately explain its relationship with the disease (Schneider et al., 2007).

SLC19A1 rs2838956 was associated with the occurrence of ALL (dominant model $A G$ ), which is similar to the results reported by De Jonge et al. (2009) who found that a $80 \mathrm{G}>$ A SNP was significantly associated with ALL for both the heterozygote and homozygote genotypes (Table 3 ). In contrast to our findings, Yeoh et al. (2010) found in their case-control study of Malaysian and Chinese populations (321 and 346 individuals, respectively) that ALL children carrying the $G>A$ genotype had protection against the disease. However, the analysis of binary combinations 
TABLE 3 | Individual risk analyses for SNPs in relation to ALL.

\begin{tabular}{|c|c|c|c|c|c|c|c|c|}
\hline Gene (SNP) & Genotype & Case $\mathbf{n}(\%)$ & Control n (\%) & OR & $95 \% \mathrm{Cl}$ & $p$-value ${ }^{*}$ & AIC & BIC \\
\hline \multicolumn{9}{|l|}{ COL18A1 (rs2274808) } \\
\hline \multirow[t]{2}{*}{ Codominant } & $C C$ & $39(53.4 \%)$ & $107(80.5 \%)$ & 1.00 & Reference & 0.0001 & 240.0 & 260.0 \\
\hline & $\pi$ & 19 (26\%) & $3(2.3 \%)$ & 21.05 & (5.62-78.87) & & & \\
\hline Dominant & $C C$ & $39(53.4 \%)$ & $107(80.5 \%)$ & 1.00 & Reference & $<0.0001$ & 248.6 & 265.2 \\
\hline \multicolumn{9}{|l|}{ SLC19A1 (rs2838956) } \\
\hline \multirow[t]{3}{*}{ Codominant } & $A A$ & $0(0 \%)$ & $48(36.1 \%)$ & 1.00 & Reference & $<0.0001$ & 200.5 & 220.5 \\
\hline & $A G$ & $71(97.3 \%)$ & $60(45.1 \%)$ & 0.00 & NA & & & \\
\hline & $G G$ & 2 (2.7\%) & 25 (18.8\%) & 0.00 & NA & & & \\
\hline Overdominant & $A A-G G$ & $2(2.7 \%)$ & 73 (54.9\%) & 1.00 & Reference & $<0.0001$ & 202.9 & 219.6 \\
\hline & CT & $23(31.5 \%)$ & $51(38.4 \%)$ & 1.67 & $(0.77-3.63)$ & & & \\
\hline & $\pi$ & 35 (48\%) & $12(9.0 \%)$ & 17.43 & $(6.91-43.97)$ & & & \\
\hline \multirow[t]{2}{*}{ Recessive } & CC-CT & 38 (52\%) & 121 (91.0\%) & 1.00 & Reference & $<0.0001$ & 223.3 & 239.9 \\
\hline & $\pi$ & 35 (48\%) & $12(9.0 \%)$ & 13.76 & $(5.94-31.88)$ & & & \\
\hline \multicolumn{9}{|l|}{ ABCB1 (rs1128503) } \\
\hline \multirow[t]{3}{*}{ Codominant } & $C C$ & 35 (48\%) & 76 (57.1\%) & 1.00 & Reference & 0.68 & 271.7 & 291.7 \\
\hline & CT & 29 (39.7\%) & 44 (33.1\%) & 1.33 & $(0.71-2.50)$ & & & \\
\hline & $\pi$ & $9(12.3 \%)$ & $13(9.8 \%)$ & 1.19 & $(0.45-3.15)$ & & & \\
\hline \multirow[t]{2}{*}{ Overdominant } & CC-TT & $44(60.3 \%)$ & 89 (66.9\%) & 1.00 & Reference & 0.13 & 236.0 & 248.5 \\
\hline & $C T$ & 29 (39.7\%) & $44(33.1 \%)$ & 1.64 & $(0.86-3.16)$ & & & \\
\hline \multicolumn{9}{|l|}{ ABCC5 (rs3792585) } \\
\hline \multirow[t]{3}{*}{ Codominant } & $\pi$ & 35 (48\%) & 93 (69.9\%) & 1.00 & Reference & 0.003 & 250.9 & 270.8 \\
\hline & $T C$ & 20 (27.4\%) & 36 (27.1\%) & 1.42 & $(0.72-2.81)$ & & & \\
\hline & $C C$ & $18(24.7 \%)$ & $4(3 \%)$ & 11.2 & $(3.50-35.91)$ & & & \\
\hline \multirow[t]{2}{*}{ Recessive } & $T T-T C$ & $55(75.3 \%)$ & 129 (97\%) & 1.00 & Reference & 0.004 & 249.9 & 266.5 \\
\hline & $C C$ & 18 (24.7\%) & $4(3 \%)$ & 9.99 & (3.19-31.28) & & & \\
\hline
\end{tabular}

AIC, Akaike Information Criterion; BIC, Bayesian Information Criterion.

" $p<0.05$.

showed that 4 SNPs are associated with a higher tendency to develop ALL, which is a new finding.

The scientific literature, as reported by Ma et al. (2015a,b) in two meta-analysis indicate no clear association between this polymorphism and risk to ALL. In our study, we found that the rs1045642 ABCB1 SNP (known as 3435C > T) was associated with a risk of ALL occurrence. This finding is in agreement with the studies by Jamroziak et al. (2004) in Polish children carrying the TT genotype and by Qian et al. (2012) in a pediatric Chinese population at risk for leukemogenesis in CT-TT vs. CC individuals. However, the study by Hua-Jie et al. showed no associations with the disease in a Chinese population (Hua-Jie et al., 2011). Moreover, the results of Drain et al. (2009) suggested that individuals carrying the $A B C B 1$ rs1045642 variation should have a beneficial impact because the overall survival rate would be extended. In our risk analysis for $A B C B 1$ rs11288503, we found no relationship between this SNP and ALL susceptibility, which contrasts the report by Ma et al. (2015a). However, when we performed the study on the combination of both SNPs ( $A B C B 1$ rs1045642+rs1128503), we observed that the rare allele 
TABLE 4 | Combined risk analyses for SNPs in relation to ALL.

\begin{tabular}{|c|c|c|c|c|c|}
\hline Combined SNPs & Case & Control & OR & $95 \% \mathrm{Cl}$ & $p$-value ${ }^{*}$ \\
\hline \multicolumn{6}{|c|}{ COL18A1 (rs2274808)+SLC19A1(rs2838956) } \\
\hline$C C+A A$ & 39 & 155 & 1.00 & - & - \\
\hline$C C+A G$ & 110 & 167 & 2.62 & $(1.71-4.01)$ & $<0.0001$ \\
\hline$C T+A G$ & 86 & 83 & 4.12 & $(2.59-6.54)$ & $<0.0001$ \\
\hline$\pi+A G$ & 90 & 66 & 5.42 & $(3.38-8.70)$ & $<0.0001$ \\
\hline$\pi+G G$ & 21 & 31 & 2.69 & (1.39-5.19) & 0.003 \\
\hline \multicolumn{6}{|c|}{ ABCB1 (rs1045642+rs1128503) } \\
\hline$C C+C C$ & 70 & 146 & 1.00 & - & - \\
\hline$T T+C T$ & 44 & 56 & 1.64 & (1.01-2.66) & 0.040 \\
\hline$\pi+\pi$ & 24 & 25 & 2.00 & $(1.06-3.75)$ & 0.029 \\
\hline \multicolumn{6}{|c|}{$A B C C 5$ (rs9838667+rs3792585) } \\
\hline$A A+\pi$ & 82 & 181 & 1.00 & - & - \\
\hline$A C+\pi$ & 50 & 181 & 0.61 & $(0.40-0.91)$ & 0.017 \\
\hline$A C+T C$ & 35 & 124 & 0.62 & (0.39-0.98) & 0.041 \\
\hline$C C+C C$ & 29 & 12 & 5.33 & $(2.59-10.97)$ & $<0.0001$ \\
\hline
\end{tabular}

"Only significant genotype combinations are included $(p<0.05)$.

combinations $(T T+C T$ and $T T+T T)$ were associated with a higher risk for ALL, which explains why children carrying such alleles are more likely to acquire the disease than those who have combinations with wild type genotypes. This result is similar to the reported by Semsei et al. (2008).

The results for the analyzed SNPs of ABCC5 (rs9838667 and rs3792585) demonstrated that only rs3792585 showed a significant association with ALL susceptibility for subjects carrying the CC genotype (Table 2). However, when both SNPs were combined only homozygote genotype combinations showed an increased risk of leukemogenesis (Table 4). Finally, the $A C+T T$ and $A C+A / T$ combinations of $A B C C 5$ were observed as protection factors for ALL (Table 4).

For the risk analyses we used inheritance models to determine risk genotypes for ALL, which is based in the idea that the rare allele modify the risk, therefore the codominant model, used as reference, explains a different risk for each genotype which are non-additive. In the dominant model the risk for heterozygote genotype is similar to the homozygote for the rare allele. Conversely, in the recessive model the wild type genotype and heterozygote genotype have similar risk. On the other hand, in the over-dominant model the wild type genotype and the homozygote for rare allele have similar risk. Finally, In the additive model the basic idea is that a copy of the allele produces half of the risk of the two alleles (Iniesta et al., 2005; Zintzaras and Lau, 2008). In this respect, we choose the most probable model (besides the codominant) for each polymorphic variants to study risk. In this sense, our results (Table 3) showed that for COL18A1 (rs2274808) the best model was de codominant, for SLC19A1 (rs2838956) was the over-dominant model, for ABCB1 (rs1045642) was the codominant, non significantly different to risk obtained from the recessive model, for the $A B C B 1$ (rs1128503) and $A B C C 5$ (rs9838667) there were not significant associations for both the codominant or over-dominant models. Finally for the ABCC5 (rs3792585) both the codominant and recessive models gave a significant risk to ALL.
One limitation of this study was the modest sample size of the cases (73). However, in our country, studies using children are quite restricted, even more whether they are patients. Moreover, considering there is an obligation to get both an informed consent and an informed assent, we believe this is a good starting number of subjects. In relation to that, there are several recent published studies with relatively small number of children (Roy Moulik et al., 2015; Amitai et al., 2016) and even more, with adults with ALL (Hareedy et al., 2015). Despite this, we truly believe our results are only a preliminary contribution regarding the ALL susceptibility of our Mexican pediatric population.

In summary, we found that 4 SNPs (COL18A1 rs2274808, SLC19A1 rs2838956, ABCB1 rs1045642, and ABCC5 rs3792585) either alone, or in some combinations, were associated with a higher risk for ALL in Mexican children. In contrast, children carrying the $A C+T T$ or $A C+T C$ combined genotypes of $A B C C 5$ seemed to be protected against ALL. These results suggest that the inter-individual variability of each patient in genes associated with the folate transport pathway influences the development of ALL.

\section{AUTHOR CONTRIBUTIONS}

FZ, Analysis, interpretation of data, design and drafting the work, final approval of the version to be published. IL, conception and design of the work, interpretation of data, critical review of the content, financial support, final approval of the version to be published. VL, Interpretation of data, critical review of the content, final approval of the version to be published. $\mathrm{AL}$, Interpretation of data, critical review of the content, final approval of the version to be published. AR, Interpretation of data, critical review of the content, final approval of the version to be published. MS, Interpretation of data, critical review of the content, final approval of the version to be published. CG, Interpretation of data, critical review of the content, final approval of the version to be published. MA, Interpretation of data, critical review of the content, final approval of the version to be published. MR, Interpretation of data, critical review of the content, final approval of the version to be published. LQ, Design of the work, interpretation of data, critical review of the content, financial support, final approval of the version to be published.

\section{FUNDING}

This work was partly financed with Chilean Fondecyt Grant no. 1140434 and the National Polytechnic Institute-CIIDIR, Durango, Mexico.

\section{ACKNOWLEDGMENTS}

The authors want to acknowledge the following people for their assistance in this research: Lic. Cristina Venzor, principal of CECAN- Nurse Service Unit, Durango-Mexico; Lic. Pedro Cruz, General Director of Oncologic Pediatric Center of Baja California, Mexico; Dr. Jesús Manuel Lozano, Medical Director of Oncologic Pediatric Center of Baja California, Mexico; and Carolyn Di Pietro-Arias for writing support. 


\section{REFERENCES}

Amitai, M., Kronenberg, S., Carmel, M., Michaelovsky, E., Frisch, A., Brent, D., et al. (2016). Pharmacogenetics of citalopram-related side effects in children with depression and/or anxiety disorders. J. Neural. Transm. (Vienna). doi: 10.1007/s00702-016-1585-7. [Epub ahead of print].

Brisson, G. D., Alves, L. R., and Pombo-De-Oliveira, M. S. (2015). Genetic susceptibility in childhood acute leukaemias: a systematic review. Ecancermedicalscience 9, 1-28. doi: 10.3332/ecancer.2015.539

Choi, C. H. (2005). ABC transporters as multidrug resistance mechanisms and the development of chemosensitizers for their reversal. Cancer Cell Int. 5:30. doi: 10.1186/1475-2867-5-30

Dagdas, S., Ozet, G., Yilmaz, M., Albayrak, M., and Ceran, F. (2011). Assessment of plasma endostatin levels in patients with acute myeloblastic and lymphoblastic leukemia. Int. J. Hematol. Oncol. 21, 210-216. doi: 10.4999/uhod.10015

De Jonge, R., Tissing, W. J., Hooijberg, J. H., Jansen, G., Kaspers, G. J., Lindemans, J., et al. (2009). Polymorphisms in folate-related genes and risk of pediatric acute lymphoblastic leukemia. Blood 113, 2284-2289. doi: 10.1182/blood-200807-165928

Digtyar, A., Pozdnyakova, N., Feldman, N., Lutsenko, S., and Severin, S. (2007). Endostatin: current concepts about its biological role and mechanisms of action. Biochemistry 72, 235-246. doi: 10.1134/S0006297907030017

Drain, S., Catherwood, M. A., Orr, N., Galligan, L., Rea, I. M., Hodkinson, C., et al. (2009). ABCB1 (MDR1) rs1045642 is associated with increased overall survival in plasma cell myeloma. Leuk. Lymphoma 50, 566-570. doi: 10.1080/10428190902853144

Galbiatti, A. L., Castro, R., Caldas, H. C., Padovani, J. A. Jr., Pavarino, E. C., and Goloni-Bertollo, E. M. (2013). Alterations in the expression pattern of MTHFR, DHFR, TYMS, and SLC19A1 genes after treatment of laryngeal cancer cells with high and low doses of methotrexate. Tumour Biol. 34, 3765-3771. doi: 10.1007/s13277-013-0960-3

Ganapathy, V., Smith, S. B., and Prasad, P. D. (2004). SLC19: the folate/thiamine transporter family. Pflugers Arch. 447, 641-646. doi: 10.1007/s00424-003-1 068-1

Gottesman, M. M., Fojo, T., and Bates, S. E. (2002). Multidrug resistance in cancer: role of ATP-dependent transporters. Nat. Rev. Cancer 2, 48-58. doi: 10.1038/nrc706

Hareedy, M. S., El Desoky, E. S., Woillard, J. B., Thabet, R. H., Ali, A. M., Marquet, P., et al. (2015). Genetic variants in 6-mercaptopurine pathway as potential factors of hematological toxicity in acute lymphoblastic leukemia patients. Pharmacogenomics 16, 1119-1134. doi: 10.2217/PGS.15.62

Higgins, C. F. (2001). ABC transporters: physiology, structure andmechanism - an overview. Res. Microbiol. 152, 205-210. doi: 10.1016/S0923-2508(01)01193-7

Holland, K. A., and Holland, I. B. (2005). Adventures with ABC-proteins: highly conserved ATP-dependent transporters. Acta Microbiol. Inmunol. Hung. 52, 309-322. doi: 10.1556/AMicr.52.2005.3-4.4

Homberger, A., Linnebank, M., Winter, C., Willenbring, H., Marquardt, T., Harms, E., et al. (2000). Genomic structure and transcript variants of the human methylenetetrahydrofolate reductase gene. Eur. J. Hum. Genet. 8, 725-729. doi: 10.1038/sj.ejhg.5200522

Hua-Jie, D., Kou-Rong, M., Chun, Q., Yun, Z., Wen-Yi, S., Ming, H., et al. (2011). Polymorphisms and haplotypes in multidrug resistance 1 gene are not associated with chronic lymphocytic leukemia susceptibility and prognostic parameters of chronic lymphocytic leukemia in Chinese population. Leuk. Lymphoma 52, 1003-1009. doi: 10.3109/10428194.2011.557454

Iniesta, R., Guinó, E., and Moreno, V. (2005). Statistical analysis of genetic polymorphisms in epidemiological studies. Gac. Sanit. 19, 333-341. doi: $10.1157 / 13078029$

Jamroziak, K., Młynarski, W., Balcerczak, E., Mistygacz, M., Treliǹska, J., Mirowski, M., et al. (2004). Functional C3435T polymorphism of MDR1 gene: an impact on genetic susceptibility and clinical outcome of childhood acute lymphoblastic leukemia. Eur. J. Haematol. 72, 314-321. doi: 10.1111/j.16000609.2004.00228. $\mathrm{x}$

Jansen, G., and Pieters, R. (1998). The role of impaired transport in (pre) clinical resistance to methotrexate: insights on new antifolates. Drug Resist. Updat. 1, 211-218. doi: 10.1016/S1368-7646(98)80042-3

Lage, H. (2008). An overview of cancer multidrug resistance: a still unsolved problem. Cell Mol. Life Sci. 65, 3145-3167. doi: 10.1007/s00018-008-8111-5
Lilleyman, J. S., Hann, I. M., Stevens, R. F., Eden, O. B., and Richards, S. M. (1986). French American British (FAB) morphological classification of childhood lymphoblastic leukaemia and its clinical importance. J. Clin. Pathol. 39, 998-1002. doi: 10.1136/jcp.39.9.998

Ma, L., Liu, H., Ruan, L., Yang, X., Yang, H., and Feng, Y. (2015a). Multidrug resistance gene $1 \mathrm{C} 1236 \mathrm{~T}$ polymorphism and susceptibility to leukemia: a meta-analysis. Biomed. Rep. 3, 83-87. doi: 10.3892/br.2014.387

Ma, L., Ruan, L., Liu, H., Yang, H., and Feng, Y. (2015b). ABCB1 C3435T polymorphism is associated with leukemia susceptibility: evidence from a meta-analysis. Onco Targets Ther. 8, 1009-1015. doi: 10.2147/OTT.S82144

Mahajan, V. B., Olney, A. H., Garrett, P., Chary, A., Dragan, E., Lerner, G., et al. (2010). Collagen XVIII mutation in Knobloch syndrome with acute lymphoblastic leukemia. Am. J. Med. Genet. A 152A, 2875-2879. doi: 10.1002/ajmg.a.33621

Moscow, J. A, Connolly, T., Myers, T. A, Cheng, C. A, Paull, K., and Cowan, K. H. (1997). Reduced folate carrier (RFC1) expression and anti-folate resistance in transfected and non-selected cell lines. Int. J. Cancer 72, 184-192.

O’leary, V. B., Pangilinan, F., Cox, C., Parle-McDermott, A., Conley, M., Molloy, A. M., et al. (2006). Reduced folate carrier polymorphisms and neural tube defect risk. Mol. Genet. Metab. 87, 364-369. doi: 10.1016/j.ymgme.2005.09.024

Pui, C.-H., Campana, D., Pei, D., Bowman, W. P., Sandlund, J. T., Kaste, S. C., et al. (2009). Treating childhood acute lymphoblastic leukemia without cranial irradiation. N. Engl. J. Med. 360, 2730-2741. doi: 10.1056/NEJMoa0 900386

Pui, C. H., Pei, D., Sandlund, J. T., Ribeiro, R. C., Rubnitz, J. E., Raimondi, S. C., et al. (2010). Long-term results of St Jude Total Therapy Studies 11, 12, 13A, 13B, and 14 for childhood acute lymphoblastic leukemia. Leukemia 24, 371-382. doi: 10.1038/leu.2009.252

Qian, X., Cao, S., Yang, G., Dong, J., Jin, G., Shen, Y., et al. (2012). Variant genotypes of MDR1 C3435T increase the risk of leukemia: evidence from 10 case-control studies. Leuk. Lymphoma 53, 1183-1187. doi: 10.3109/10428194.2011.641179

Rodríguez, L., González-Llano, O., Mancias, C., Pompa, T., González, G., Sandoval, A., et al. (2010). Observaciones sobre la incidencia de leucemias agudas en el Noreste de México. Rev. Hematol. Mex. 11, 78-81.

Ross, D. D., and Doyle, L. A. (2004). Mining our ABCs: pharmacogenomic approach for evaluating transporter function in cancer drug resistance. Cancer Cell 6, 105-107. doi: 10.1016/j.ccr.2004.08.003

Roy Moulik, N., Kumar, A., Agrawal, S., Awasthi, S., Mahdi, A. A., and Kumar, A. (2015). Role of folate status and methylenetetrahydrofolate reductase genotype on the toxicity and outcome of induction chemotherapy in children with acute lymphoblastic leukemia. Leuk. Lymphoma 56, 1379-1384. doi: 10.3109/10428194.2014.947608

Schneider, P., Vasse, M., Corbiere, C., Legrand, E., Marie-Cardine, A., Boquet, C., et al. (2007). Endostatin variations in childhood acute lymphoblastic leukaemicomparison with basic fibroblast growth factor and vascular endothelial growth factor. Leuk. Res. 31, 629-638. doi: 10.1016/j.leukres.2006.08.023

Semsei, Á. F., Erdélyi, D. J., Ungvári, I., Kámory, E., Csókay, B., Andrikovics, H., et al. (2008). Association of some rare haplotypes and genotype combinations in the MDR1 gene with childhood acute lymphoblastic leukaemia. Leuk. Res. 32, 1214-1220. doi: 10.1016/j.leukres.2007.12.009

Sertie, A., Sossi, V., Camargo, A., Zatz, M., Brahe, C., and Passos-Bueno, M. (2000). Collagen XVIII, containing an endogenous inhibitor of angiogenesis and tumor growth, plays a critical role in the maintenance of retinal structure and in neural tube closure (Knobloch syndrome). Hum. Mol. Genet. 9, 2051-2058. doi: 10.1093/hmg/9.13.2051

Sirotnak, F. M., and Tolner, B. (1999). Carrier-mediated membrane transport of folates in mammalian cells. Annu. Rev. Nutr. 19, 91-122 doi: 10.1146/ annurev.nutr.19.1.91

Skibola, C. F., Smith, M. T., Kane, E., Roman, E., Rollinson, S., Cartwright, R. A., et al. (1999). Polymorphisms in the methylenetetrahydrofolate reductase gene are associated with susceptibility to acute leukemia in adults. Proc. Natl. Acad. Sci. U.S.A. 96, 12810-12815. doi: 10.1073/pnas.96.22.12810

Solé, X., Guinó, E., Valls, J., Iniesta, R., and Moreno, V. (2006). SNPStats: a web tool for the analysis of association studies. Bioinformatics 22, 1928-1929. doi: 10.1093/bioinformatics/btl268

Steinberg, K. K., Relling, M. V., Gallagher, M. L., Greene, C. N., Rubin, C. S., French, D., et al. (2007). Genetic Studies of a cluster of acute lymphoblastic 
leukemia cases in churchill county, nevada. Environ. Health Perspect. 115, 158-164. doi: 10.1289/ehp. 9025

Takatori, R., Takahashi, K. A., Tokunaga, D., Hojo, T., Fujioka, M., Asano, T., et al. (2006). ABCB1 C3435T polymorphism influences methotrexate sensitivity in rheumatoid arthritis patients. Clin. Exp. Rheumatol. 24, 546-554.

Warren, M. S., Zerangue, N., Woodford, K., Roberts, L. M., Tate, E. H., Feng, B., et al. (2009). Comparative gene expression profiles of ABC transporters in brain microvessel endothelial cells and brain in five species including human. Pharmacol. Res. 59, 404-413. doi: 10.1016/j.phrs.2009.02.007

Wielinga, P., Hooijberg, J. H., Gunnarsdottir, S., Kathmann, I., Reid, G., Zelcer, N., et al. (2005). The human multidrug resistance protein MRP5 transports folates and can mediate cellular resistance against antifolates. Cancer Res. 65, 4425-4430. doi: 10.1158/0008-5472.CAN-04-2810

Wolking, S., Schaeffeler, E., Lerche, H., Schwab, M., and Nies, A. T. (2015). Impact of genetic polymorphisms of ABCB1 (MDR1, P-Glycoprotein) on drug disposition and potential clinical implications: update of the literature. Clin. Pharmacokinet. 54, 709-735. doi: 10.1007/s40262-015-0267-1

Yeoh, A. E. J., Lu, Y., Chan, J. Y. S., Chan, Y. H., Ariffin, H., Kham, S. K. Y., et al. (2010). Genetic susceptibility to childhood acute lymphoblastic leukemia shows protection in malay boys: results from the malaysia-singapore all study group. Leuk. Res. 34, 276-283. doi: 10.1016/j.leukres.2009.07.003
Zeller, B., Gustafsson, G., Forestier, E., Abrahamsson, J., Clausen, N., Heldrup, J., et al. (2005). Acute leukaemia in children with Down syndrome: a population-based Nordic study. Br. J. Haematol. 128, 797-804. doi: 10.1111/ j.1365-2141.2005.05398.x

Zintzaras, E., and Lau, J. (2008). Synthesis of genetic association studies for pertinent gene-disease associations requires appropriate methodological and statistical approaches. J. Clin. Epidemiol. 61, 634-645. doi: 10.1016/j.jclinepi. 2007.12.011

Conflict of Interest Statement: The authors declare that the research was conducted in the absence of any commercial or financial relationships that could be construed as a potential conflict of interest.

Copyright (C) 2016 Zaruma-Torres, Lares-Asseff, Lima, Reyes-Espinoza, Loera-Castañeda, Sosa-Macías, Galaviz-Hernández, Arias-Peláez, Reyes-López and Quiñones. This is an open-access article distributed under the terms of the Creative Commons Attribution License (CC BY). The use, distribution or reproduction in other forums is permitted, provided the original author(s) or licensor are credited and that the original publication in this journal is cited, in accordance with accepted academic practice. No use, distribution or reproduction is permitted which does not comply with these terms. 